\title{
Konstruksi Metode Transformasi Diferensial Multi-Step (Multi-Step Differential Transform Method) untuk Model SEIRS Autonomous dan Nonautonomous
}

\author{
Esther Y. Bunga, Jusrry R. Pahnael, Maria Lobo, Meksianis Z. NdiI \\ Program Studi Matematika, Fakultas Sains dan Teknik, Universitas Nusa Cendana \\ email :meksians.ndii@staf.undana.ac.id
}

\begin{abstract}
Abstrak
Pemodelan matematika telah banyak digunakan untuk memahami permasalahan nyata. Model matematika dapat diselesaikan secara analitik. Namun, apabila model matematika tersebut semakin kompleks, maka solusi analitik tidak mudah diperoleh dan pendekatan numerik digunakan. Dalam artikel ini, pendekatan numerik dengan Metode Transformasi Diferensial (MTD) multi-step yang menghasilkan solusi deret konvergen digunakan untuk mencari solusi dari model matematika penyebaran penyakit SEIRS yang autonomous dan non-autonomous. Metode ini dikenal juga dengan metode semi analitik karena kita dapat menuliskan solusi analitik dari model yang dicarikan solusinya. Dalam artikel akan dikonstruksi metode tranformasi diferensial untuk model SEIRS autonomous dan nonautonomous dan menganalisis akurasi dengan cara membandingkan dengan metode Runge-Kutta. Metode transformasi diferensial multi-step dapat memberikan aproksimasi solusi yang baik dari model matematika SEIRS autonomous dan non-autonomous. Namun, kinerja dari metode ini lebih baik pada model autonomous.

Kata Kunci:Transformasi Diferensial, Model SEIRS, Metode Numerik
\end{abstract}

\begin{abstract}
Mathematical modeling has been widely used to understand real problems. The solutions of a mathematical model can be obtained analytically. However, when the model becomes complex, it is not analytically tractable and therefore, numerical approach has been used. In this article, The Multi Step Differential Transformation (MTD) has been constructed for solving SEIRS autonomous and nonautonomous epidemic models. The results are compared to that produced by the Runge-Kutta method, a widely used method. It is found that the Multi Step Differential transformation method can provide a good approximation of the solution of SEIRS autonomous and nonautonomous epidemic model where the performance of the method for solving autonomous model is better.

Keywords:Diffrential transformation method, SEIRS model, Numerical method
\end{abstract}

2000 Mathematics Subject Classification: 37C05

Submitted: 2020-06-04 Revised: 2020-06-19, accepted: 2020-06-19 


\section{Pendahuluan}

Pemodelan matematika telah banyak digunakan untuk memahami permasalahan nyata seperti penyebaran penyakit atau rumor [1, 2]. Apabila model matematika sederhana, solusi analitik masih mudah diperoleh. Sebaliknya jika model matematika semakin kompleks, maka solusi analitik tidak mudah diperoleh dan oleh karena itu, pendekatan numerik lebih sering digunakan. Pendekatan numerik yang umumnya digunakan adalah Runge-Kutta, Euler, Skema Beda Hingga. Sejauh ini, penyelesaian numerik dengan mengkonstruksi metode transformasi diferensial sangat jarang digunakan. Hal ini diduga karena pemahaman mengenai metode ini yang masih sangat kurang. Beberapa riset yang menggunakan metode ini dapat dilihat pada $[3,4,5,6,7,8])$.

Metode Transformasi Diferensial (MTD) adalah metode numerik dan analitik (semianalitik) yang digunakan untuk menyelesaikan masalah persamaan diferensial dengan memberikan solusi dalam deret konvergen. Konsep transformasi diferensial pertama kali diusulkan oleh Zhou [9] dan aplikasi utamanya berkaitan dengan masalah nilai awal linear dan tak linear dalam analisis rangkaian listrik. MTD memberikan nilai yang tepat dari turunan ke-n dari fungsi analitik pada suatu titik dalam kondisi batas yang diketahui. MTD digunakan untuk memberikan solusi perkiraan untuk masalah tak linear dalam deret konvergen dengan komponen yang mudah dihitung. Akan tetapi, MTD memiliki beberapa kelemahan, yaitu solusi deret hanya berlaku untuk masalah sederhana sedangkan tingkat konvergensi untuk masalah yang lebih luas menjadi lebih sulit untuk dihitung. Untuk mengatasi kekurangan tersebut, telah dikembangkan MTD Multi-Step. Metode ini digunakan untuk memberikan solusi numerik persamaan diferensial dengan mempertimbangkan masalah nilai awal tak linear.

Dalam artikel ini, MTD Multi-Step digunakan untuk mengkonstruksi solusi untuk model penyebaran penyakit SEIRS autonomous dan nonautonomous. Pada model ini populasi dibagi kedalam kelompok menurut status kesehatannya yakni Rentan (S), Terpapar (E), Terinfeksi (I), dan Sembuh (R). Pada model SEIRS autonomous, laju penulara penyakit bernilai konstan sedangkan pada model nonautonomous, laju penyebaran penyakit adalah fungsi dari waktu. Keakuratan MTD Multi-Step akan diamati dengan cara membandingkannya dengan metode Runge-Kutta yang merupakan metode yang paling sering digunakan.

\section{Metode}

2.1. Model Matematika. Model matematika yang digunakan adalah model matematika SEIRS, yang merupakan model dalam masalah epidemiologi khususnya model untuk dinamika penyebaran penyakit menular, dimana populasi dibagi kedalam kelompok yang berbeda sesuai dengan kelasnya: kelompok rentan (S), terpapar (E), terinfeksi (I) dan sembuh (R) [10]. Pada model ini juga dipertimbangkan waning immunity yakni individu yang telah sembuh dapat kembali lagi menjadi individu rentan setelah beberapa periode waktu. Model matematika SEIR adalah sebagai berikut

$$
\begin{aligned}
\frac{d S}{d t} & =\mu N-\beta \frac{S I}{N}-\mu S+v R, \\
\frac{d E}{d t} & =\beta \frac{S I}{N}-(\delta+\mu) E, \\
\frac{d I}{d t} & =\delta E-\gamma I-\mu I, \\
\frac{d R}{d t} & =\gamma I-v R-\mu R,
\end{aligned}
$$

dimana laju transmisi $\beta$ konstan pada model autonomous dan $\beta(t)=\beta_{0}(1+\eta \sin (2 \pi t+\omega))$ untuk kasus non-autonomous. 


\subsection{Transformasi Diferensial Multi-Step.}

Definisi 2.1. Diberikan $f(x)$ adalah fungsi terdiferensialkan maka transformasi diferensial dari turunan ke $k$ adalah fungsi yang didefinisikan sebagai

$$
F(k)=\frac{1}{k !}\left[\frac{d^{k} f(x)}{d t^{k}}\right]
$$

dimana $f(x)$ is fungsi sebelum transformasi (fungsi awal) and $F(x)$ adalah fungsi transformasi.

Definisi 2.2. Invers diferensial dari fungsi transformasi didefinisikan sebagai

$$
f(x)=\sum_{k=0}^{\infty} F(k)\left(x-x_{0}\right)^{k}
$$

Dari kedua persamaan diatas (Persamaan (2) and (3)) diperoleh

$$
f(x)=\left.\sum_{k=0}^{\infty} \frac{\left(x-x_{0}\right)^{k}}{k !} \frac{d^{k} f(x)}{d x^{k}}\right|_{x=x_{0}} .
$$

Dari Persamaan (4) terlihat bahwa konsep DTM diperoleh dari ekspansi deret Taylor. Dalam penerapannya, fungsi $f(x)$ diekspresikan dalam deret berhingga yakni

$$
f(x)=\sum_{k=0}^{n} F(k)\left(x-x_{0}\right)^{k} .
$$

Metode ini sering dikenal dengan metode transformasi diferensial klasik. Metode transformasi diferensial multi-step menggunakan langkah pada MTD klasik pada setiap selang waktu [11]. Metode MTD multi-step sebagai berikut.

Misalkan akan dicari solusi pada selang waktu $(0, X)$ dan domain waktu tersebut dibagi kedalam $m$ sub-interval $\left[x_{m-1}, x_{m}\right]$. Untuk domain waktu yang pertama, $\left[0, x_{1}\right]$, solusi dari dari sistem diaproksimasi dengan menggunakan

$$
f_{1}(x)=\sum_{k=0}^{n} F_{1}(k) x^{k} .
$$

dengan kondisi awal $f_{1}(0)=f_{0}$. Untuk sub-interval selanjutnya, $m \geq 2,\left[x_{m-1}, x_{m}\right]$, kondisi awal adalah nilai $f(x)$ pada waktu akhir $t$ dari sub-interval waktu sebelumnya $f_{m-1}(m-1)=$ $f_{m}(0)$ dan solusi diaproksimasi

$$
f_{m}(x)=\sum_{k=0}^{n} F_{m}(k)\left(x-x_{m-1}\right)^{k}, \quad x \in\left(x_{m-1}, x_{m}\right)
$$

Dengan demikian, solusinya adalah gabungan dari solusi pada masing-masing sub-interval sebagai berikut

$$
f(x)= \begin{cases}f_{1}(x), & t \in\left(0, x_{1}\right), \\ f_{2}(x), & t \in\left(x_{1}, x_{2}\right) \\ \vdots & \\ f_{m}(x), & t \in\left(x_{m-1}, x_{m}\right)\end{cases}
$$

Dengan menggunakan definisi 2.1 and 2.2, sifat-sifat dari operasi transformasi diferensial diberikan pada Tabel $1[5,6]$. 
TABEL 1. Operation of differential transform

\begin{tabular}{ll}
\hline Original function & Transformed function \\
\hline$f(t)=u(t)+v(t)$ & $F(z)=U(z)+V(z)$ \\
$f(t)=a u(t)$ & $F(z)=a U(z)$ \\
$f(t)=u(t) v(t)$ & $F(z)=\sum_{l=0}^{k} V(l) U(z-1)$ \\
$f(t)=u(t) v(t) w(t)$ & $F(z)=\sum_{l=0}^{k} \sum_{m=0}^{l} W(m) V(l-m) U(k-1)$ \\
$f(t)=\frac{d^{m} u(t)}{d t^{m}}$ & $F(z)=(z+1)(z+2)(z+3) \ldots(z+m) U(z+m)$ \\
$f(t)=\frac{d u(t)}{d t}$ & $F(z)=(z+1) F(k+1)$ \\
$f(t)=\sin (\alpha t+\omega)$ & $F(z)=\frac{\alpha^{k}}{k !} \sin \left(\frac{\phi k}{2}+\omega\right)$ \\
\hline
\end{tabular}

\section{Hasil DAN Pembahasan}

3.1. Transformasi dari model matematika. Dari Model (1), misalkan $N$ adalah total populasi, $\hat{S}=S / N, \hat{E}=E / N, \hat{I}=I / N, \hat{R}=R / N$ dan substitusikan ke Persamaan (1), maka diperoleh model matematika dalam proporsi sebagai berikut

$$
\begin{aligned}
\frac{d S}{d t} & =\mu-\beta S I-\mu S+v R, \\
\frac{d E}{d t} & =\beta S I-(\delta+\mu) E, \\
\frac{d I}{d t} & =\delta E-\gamma I-\mu I, \\
\frac{d R}{d t} & =\gamma I-v R-\mu R,
\end{aligned}
$$

Dengan menggunakan sifat-sifat pada Tabel 1, Model 9 kemudian ditransformasikan. Misalkan $\mathbf{S}, \mathbf{E}, \mathbf{I}$ and $\mathbf{R}$ adalah fungsi transformasi dari $S, E, I$ dan $R$, maka diperoleh fungsi transformasi dari Model 9 adalah

$$
\begin{aligned}
& \mathbf{S}(\mathbf{k}+\mathbf{1})=\frac{1}{k+1}\left(\mu-\beta \sum_{l=0}^{k} \mathbf{I}(\mathbf{l}) \mathbf{S}(\mathbf{k}-\mathbf{l})-\mu \mathbf{S}(\mathbf{k})+v \mathbf{R}(\mathbf{k})\right) \\
& \mathbf{E}(\mathbf{k}+\mathbf{1})=\frac{1}{k+1}\left(\beta \sum_{l=0}^{k} \mathbf{I}(\mathbf{l}) \mathbf{S}(\mathbf{k}-\mathbf{l})-(\delta+\mu) \mathbf{E}(\mathbf{k})\right) \\
& \mathbf{I}(\mathbf{k}+\mathbf{1})=\frac{1}{k+1}(\delta \mathbf{E}(\mathbf{k})-(\gamma+\mu) \mathbf{I}(\mathbf{k})) \\
& \mathbf{R}(\mathbf{k}+\mathbf{1})=\frac{1}{k+1}(\gamma \mathbf{I}(\mathbf{k})-(v+\mu) \mathbf{R}(\mathbf{k}))
\end{aligned}
$$

Dengan menggunakan fungsi transformasi (10), maka solusi dari Model(9) adalah invers dari Persamaan (10),

$$
\begin{aligned}
& S\left(t_{1}\right)=\sum_{k=0}^{N} \mathbf{S}(\mathbf{k})\left(t-t_{0}\right)^{k} \quad t \in\left[\begin{array}{ll}
t_{0} & t_{1}
\end{array}\right] \quad \text { dan } \quad S\left(t_{m}\right)=\sum_{k=0}^{N} \mathbf{S H}(\mathbf{k})\left(t-t_{m-1}\right)^{k} \quad t \in\left[\begin{array}{ll}
t_{m-1} & t_{m}
\end{array}\right], \\
& E\left(t_{1}\right)=\sum_{k=0}^{N} \mathbf{E}(\mathbf{k})\left(t-t_{0}\right)^{k} \quad t \in\left[\begin{array}{ll}
t_{0} & t_{1}
\end{array}\right] \quad \text { and } \quad E\left(t_{m}\right)=\sum_{k=0}^{N} \mathbf{E}(\mathbf{k})\left(t-t_{m-1}\right)^{k} \quad t \in\left[\begin{array}{ll}
t_{m-1} & t_{m}
\end{array}\right], \\
& I\left(t_{1}\right)=\sum_{k=0}^{N} \mathbf{I}(\mathbf{k})\left(t-t_{0}\right)^{k} \quad t \in\left[\begin{array}{ll}
t_{0} & t_{1}
\end{array}\right] \quad \text { dan } \quad I\left(t_{m}\right)=\sum_{k=0}^{N} \mathbf{I}(\mathbf{k})\left(t-t_{m-1}\right)^{k} \quad t \in\left[\begin{array}{ll}
t_{m-1} & t_{m}
\end{array}\right] \\
& R\left(t_{1}\right)=\sum_{k=0}^{N} \mathbf{R}(\mathbf{k})\left(t-t_{0}\right)^{k} \quad t \in\left[\begin{array}{ll}
t_{0} & t_{1}
\end{array}\right] \quad \text { dan } \quad R\left(t_{m}\right)=\sum_{k=0}^{N} \mathbf{R}(\mathbf{k})\left(t-t_{m-1}\right)^{k} \quad t \in\left[\begin{array}{ll}
t_{m-1} & t_{m}
\end{array}\right] .
\end{aligned}
$$


Kondisi awal untuk selang waktu yang pertama adalah $\mathbf{S}(\mathbf{0})=S_{0}, \mathbf{E}(\mathbf{0})=E_{0}, \mathbf{I}(\mathbf{0})=I_{0}$, $\mathbf{R}(\mathbf{0})=R_{0}$. Pada selang waktu selanjutnya, kondisi awal adalah nilai pada waktu terakhir selang waktu sebelumnya.

Persamaan (10) adalah transformasi untuk model autonomous. Untuk model nonautonomous, laju penularan penyakit adalah

$$
\beta(t)=\beta_{0}(1+\eta \sin (2 \pi t+\omega))=\beta_{0}+\beta_{0} \eta \sin (2 \pi t+\omega)
$$

Fungsi transformasi dari laju penularan adalah

$$
\beta(k)=\beta_{0}+\beta_{0} \eta \frac{(2 \pi)^{k}}{k !} \sin \left(\frac{\pi k}{2}+\omega\right) .
$$

Dengan demikian, model transformasi untuk SEIRS nonautonomous adalah

$$
\begin{aligned}
\mathbf{S}(\mathbf{k}+\mathbf{1}) & =\frac{1}{k+1}\left(\mu-\sum_{k_{2}=0}^{k} \sum_{k_{1}=0}^{k_{2}} \beta\left(k_{1}\right) \mathbf{I}\left(k-k_{2}\right) \mathbf{S}\left(k_{2}-k_{1}\right)-\mu \mathbf{S}(\mathbf{k})+v \mathbf{R}(\mathbf{k})\right) \\
\mathbf{E}(\mathbf{k}+\mathbf{1}) & =\frac{1}{k+1}\left(\sum_{k_{2}=0}^{k} \sum_{k_{1}=0}^{k_{2}} \beta\left(k_{1}\right) \mathbf{I}\left(k-k_{2}\right) \mathbf{S}\left(k_{2}-k_{1}\right)-(\delta+\mu) \mathbf{E}(\mathbf{k})\right) \\
\mathbf{I}(\mathbf{k}+\mathbf{1}) & =\frac{1}{k+1}(\delta \mathbf{E}(\mathbf{k})-(\gamma+\mu) \mathbf{I}(\mathbf{k})) \\
\mathbf{R}(\mathbf{k}+\mathbf{1}) & =\frac{1}{k+1}(\gamma \mathbf{I}(\mathbf{k})-(v+\mu) \mathbf{R}(\mathbf{k}))
\end{aligned}
$$

Solusinya adalah invers dari Persamaan (13).
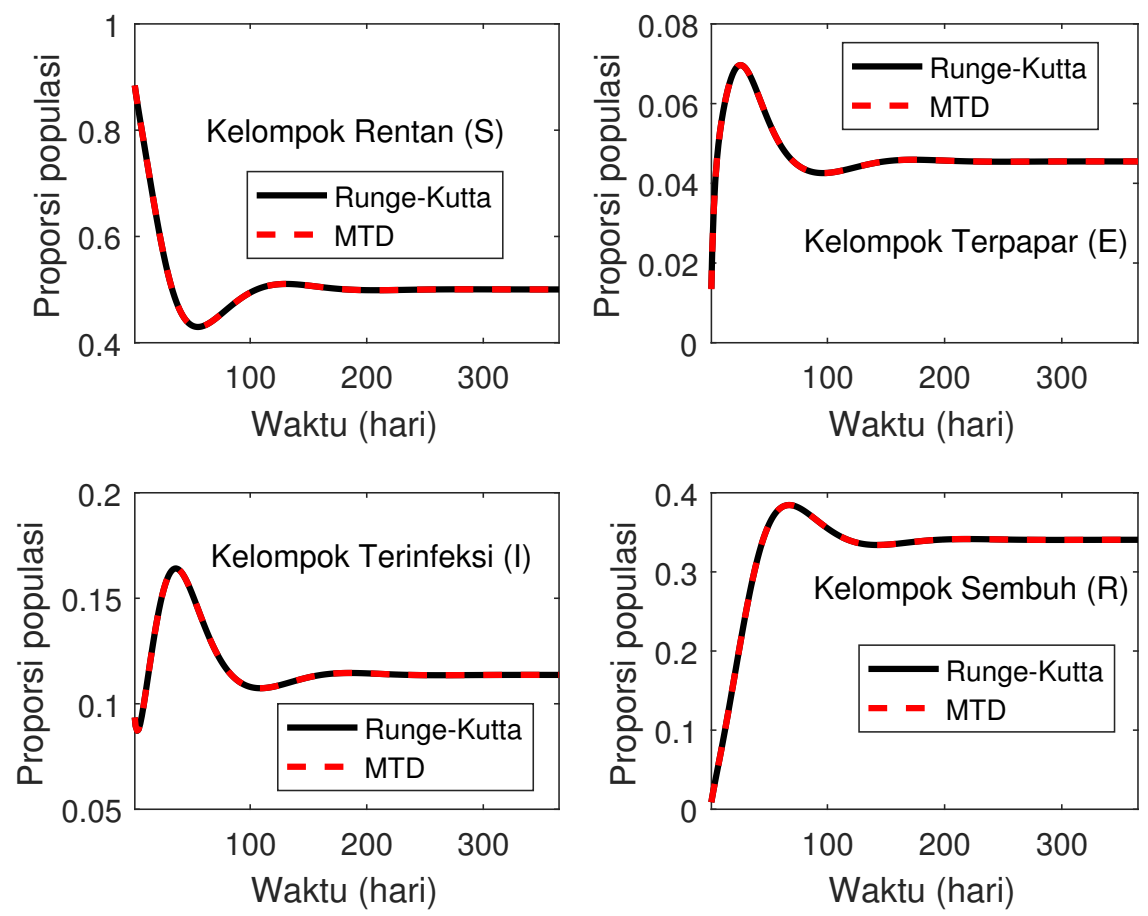

Gambar 1. Simulasi Numerik antara Runge-Kutta dan Metode Transformasi Diferensial Multi-Step untuk model autonomous dan selang waktu adalah 0.01. 
3.2. Simulasi Numerik. Pada bagian ini akan diberikan solusi numerik dari model diatas dengan menggunakan metode transformasi diferensial multi-step. Hasil simulasi dari metode Transformasi Diferensial Multi Step akan dibandingkan dengan metode Runge-kutta yang merupakan metode yang paling sering digunakan untuk menyelesaikan sistem persamaan diferensial. Nilai parameter yang digunakan adalah $\beta=0.5$ day $^{-1}, \delta=1 / 4$ day $^{-1}, \mu=1 /(65 \times 365)$ day $^{-1}$, $v=1 / 20, \gamma=1 / 10$ day $^{-1}[12]$.

Gambar 1 menunjukkan bahwa TDM dan Metode Rungge-Kutta memberikan solusi yang serupa. Untuk model SEIRS autonomous, kedua metode memberikan solusi yang serupa dan time-step adalah 0.01 .
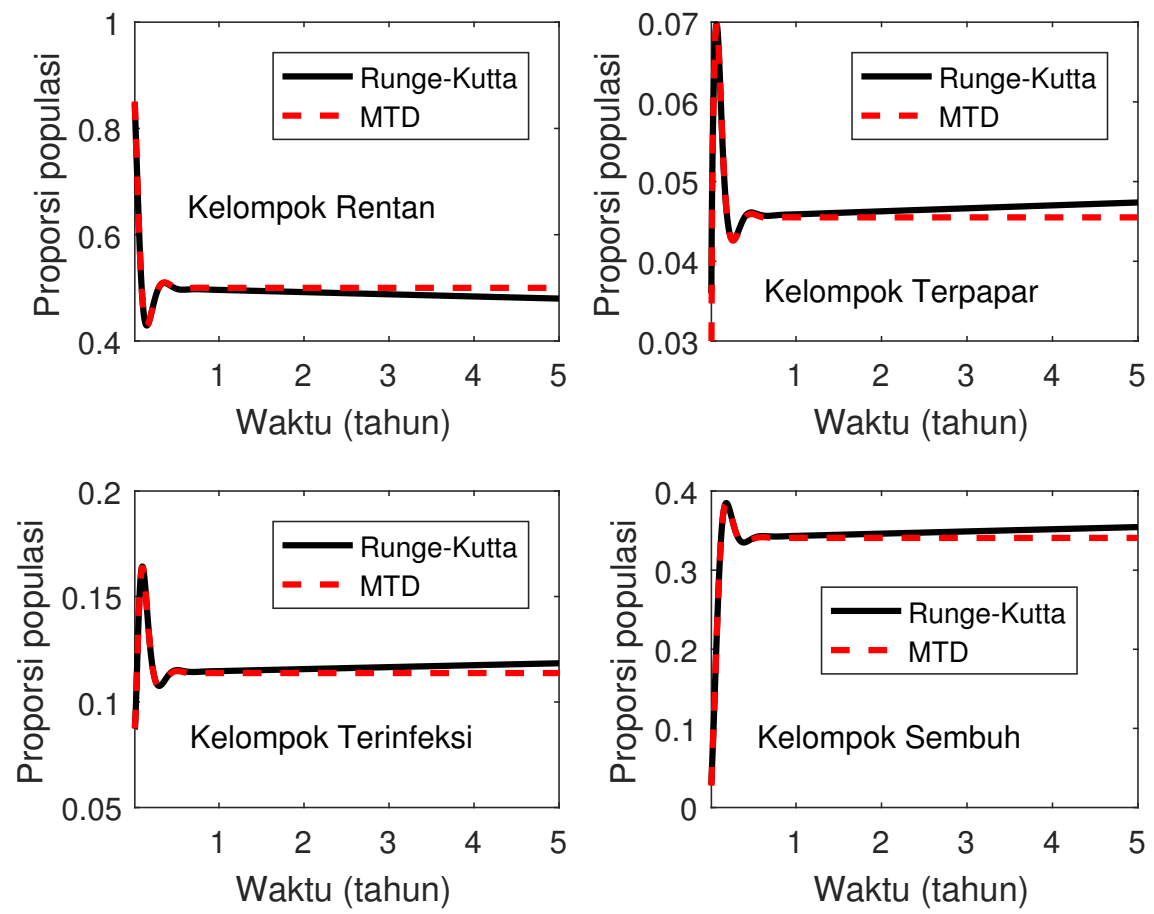

Gambar 2. Simulasi Numerik antara Runge-Kutta dan Metode Transformasi Diferensial Multi-Step untuk model nonautonomous dan selang waktu adalah 0.0001 .

Gambar 2 menunjukkan bahwa pada waktu awal, secara umum metode transformasi diferensial memberikan solusi yang serupa dengan metode Runge-Kutta, walaupun errornya sedikit besar ketika ditahun ke lima. Time-step yang digunakan adalah 0.0001. Jika digunakan time-step yang lebih kecil, maka DTM multi step maka error yang diperoleh menjadi lebih besar untuk model non-autonomous.

\section{Diskusi DAN Simpulan}

Hasil penelitian menunjukkan bahwa metode transformasi diferensial multi step dapat digunakan untuk penyelesaian numerik dari sistem persamaan diferensial. Metode ini dapat menjadi alternatif metode dalam penyelesaian sistem persamaan diferensial. Walaupun demikian, waktu yang dibutuhkan untuk menghasilkan solusi lebih panjang dibandingkan dengan metode Runge-Kutta. Selain itu, pemilihan selang waktu juga menjadi penting. Apabila selang waktu makin lebar, maka akan mempengaruhi keakuratan dari solusi. Metode transformasi diferensial sudah dibandingkan dengan metode lain seperti nonstandard finite difference 
scheme [3] dan memberikan hasil yang sejalan dengan keakuratan yang juga tinggi. Walaupun demikian, time-step juga harus dipilih yang kecil sehingga error yang dihasilkan kecil. Aplikasi dari metode nonstandard finite difference scheme pada model penyebaran penyakit dibahas pada $[13,3]$.

\section{DAFTAR PUSTAKa}

[1] N. Anggriani, H. Tasman, M. Ndii, A. Supriatna, E. Soewono, and E. Siregar, "The effect of reinfection with the same serotype on dengue transmission dynamics," Applied Mathematics and Computation, vol. 349, pp. $62-80,2019$.

[2] M. Z. Ndii, E. Carnia, and A. K. Supriatna, "Mathematical models for the spread of rumors: A review," in Issues and Trends in Interdisciplinary Behavior and Social Science: Proceedings of the 6th International Congress on Interdisciplinary Behavior and Social Sciences (ICIBSoS 2017), July 22-23, 2017, Bali, Indonesia (F. L. Gaol, ed.), USA: CRC Press, 2018.

[3] M. Z. Ndii, N. Anggriani, and A. K. Supriatna, "Comparison of the differential transformation method and non standard finite difference scheme for solving plant disease mathematical model," Communication in Biomathematical Sciences, vol. 1, no. 2, 2018.

[4] I. A.-H. Hassan, "Application to differential transformation method for solving systems of differential equations," Applied Mathematical Modelling, vol. 32, no. 12, pp. 2552 - 2559, 2008.

[5] Z. M. Odibat, C. Bertelle, M. Aziz-Alaoui, and G. H. Duchamp, "A multi-step differential transform method and application to non-chaotic or chaotic systems," Computers and Mathematics with Applications, vol. 59, no. 4, pp. 1462-1472, 2010.

[6] A. J. Arenas, G. Gonzales-Parra, and B. M. Chen-Charpentier, "Dynamical analysis of the transmission of seasonal disease using the differential transformation method," Mathematical and Computer Modelling, vol. 50, pp. 765-776, 2009.

[7] M. Hatami, D. Domairry, and M. Sheikholeslami, Differential Transformation Method for Mechanical Engineering Problems. United Kingdom: Springer, 2017.

[8] M. Z. Ndii, N. Anggriani, and A. K. Supriatna, "Application of differential transformation method for solving dengue transmission mathematical model," Symposium on Biomathematics. AIP Conference Proceeding, 2018.

[9] J. K. Zhou, Differential Transformation and Its Applications for Electrical Circuits. Wuhan, China (in Chinese): Huazhong University Press, 1986.

[10] R. U. Hurint, M. Z. Ndii, and M. Lobo, "Analisis sensitivitas dari model epidemi SEIR," Natural Science: Journal of Science and Technology, vol. 6, no. 1, pp. 22-28, 2017.

[11] M. Nourifar, A. A. Sani, and A. Keyhani, "Efficient multi-step differential transform method: Theory and its application to nonlinear oscillators," Commun Nonlinear Sci Numer Simulat, vol. 53, pp. 154-183, 2017.

[12] A. B. Hogan, K. Glass, H. C. Moore, and R. S. Anderssen, "Age structures in mathematical models for infectious diseases, with a case study of respiratory syncytial virus," in Applications + Practical Conceptualization + Mathematics $=$ fruitful Innovation (R. S. Anderssen, P. Broadbridge, Y. Fukumoto, K. Kajiwara, T. Takagi, E. Verbitskiy, and M. Wakayama, eds.), (Tokyo), pp. 105-116, Springer Japan, 2016.

[13] A. Suryanto, W. M. Kusumawinahyu, I. Darti, and I. Yanti, "Dynamically consistent discrete epidemic model with modified saturated incidence rate," Computational and Applied Mathematics, vol. 32, pp. 373$383,2013$. 
